\title{
APONTAMENTOS ECOCRÍTICOS SOBRE A PEÇA MAHAGONNY, DE BERTOLT BRECHT
}

http://dx.doi.org/10.11606/issn.2237-1184.v0i32p99-113

Klaus Eggensperger ${ }^{\mathrm{I}}$

\section{RESUM0}

O presente artigo apresenta a peça musical "Ascensão e queda da cidade de Mahagonny", da fase áurea da colaboração entre Bertolt Brecht e Kurt Weill. Nossa leitura ecocrítica do libreto brechtiano focaliza no tratamento que os elementos do mundo natural recebem na peça, além de investigar a relação entre a comunidade humana de Mahagonny e a natureza em geral. Analisamos a ameaça de destruição da cidade por um furacão em relação à ideia do sublime formulada por Kant e Schiller e retomada por Lyotard duzentos anos mais tarde. Finalmente, retomamos a questão da relação humanos - natureza na peça a fim de levantar o problema básico que nos assalta hoje: a destruição ambiental a nível planetário resultante da globalização do modelo Mahagonny.

\section{ABSTRACT}

This article presents the musical "Rise and Fall of the City of Mahagonny", dating from the Golden Age of collaboration between Bert Brecht and Kurt Weill in Germany. Our ecocritical reading of the libretto is focusing on the treatment that elements of the natural world receive in the opera and on the human nature relationship in general. We analyze the threat of destruction of the city by a hurricane in relation to the idea of the sublime formulated by Kant and Schiller and taken up by Lyotard two hundred years later. Finally, we return to the question of the human - nature relationship in the play in order to raise the basic problem that strikes us today: planetary environmental destruction resulting from the globalization of the model named Mahagonny.

\section{PALAVRAS-CHAVE:}

Ecocriticismo;

Bertolt Brecht;

Mahagonny;

Letras estrangeiras modernas.

I Universidade Federal do Paraná, Curitiba, Paraná, Brasil. 
O que é a fúria de um tufão Comparada ao homem quando quer se divertir?

(BRECHT, 2004, p. 131)

\section{$\int$ ntrodução}

Em Ascensão e queda da cidade de Mahagonny, um dos mais importantes resultados da cooperação artística de Bertolt Brecht com o compositor Kurt Weill no final dos anos 20 do século passado, narra-se a fundação e o rápido desenvolvimento de uma cidade que tem um único objetivo: oferecer a seus fregueses masculinos diversão paga. A cidade, diz sua fundadora, a viúva Begbick, "[...] soll sein wie ein Netz/ Dass für die essbaren Vögel gestellt wird/ Überall gibt es Mühe und Arbeit/ Aber hier gibt es Spass./ Denn es ist/ die Wollust der Männer/ Nicht zu leiden und alles zu dürfen" (BRECHT, 1998, p. 336). ${ }^{1}$

Assim como um outro e mais famoso fruto da dupla Brecht/Weill, a Ópera dos três vinténs, a ópera Mahagonny é consistente no seu antinaturalismo e anti-ilusionismo. Uma das versões preliminares da peça, o musical (Songspiel) Mahagonny, de 1927, acaba com os seguintes versos: "Mahagonny - das gibt es nicht./ Mahagonny - das ist kein Ort./ Mahagonny das ist nur ein erfundenes Wort." (BRECHT, 1988, p. 331); em português: Mahagonny não existe, não é nenhum local, é somente uma palavra inventada, tradução nossa). Podemos contestar essa enunciação, lembrando o conhecido bon mot de Oscar Wilde que ressalta que a vida imita a arte muito mais do que a arte imita a vida. Um ano após a estreia da versão definitiva da ópera Mahagonny, começa a ascensão de um lugarejo chamado Las Vegas no meio do deserto de Nevada, no estado americano pioneiro em permitir e instalar a indústria do jogo. Os primeiros a gastar seu dinheiro com álcool, sexo e jogo foram os milhares de trabalhadores empregados na construção de uma enorme barragem hidroelétrica no deserto, que disponibilizaria água e eletricidade em abundância. Nos anos quarenta e cinquenta, a cidade arapuca Las Vegas Sin City, cidade dos pecados, como é conhecida a partir dos filmes de Hollywood - já oferecia hotéis gigantescos, casinos e caça-níqueis, shows

1 “[...] vai ser como a arapuca/ Que se arma para os passarinhos./ Em toda parte se dá duro e se trabalha./ Mas aqui se goza,/ Porque este é o desejo dos homens:/ Não sofrer nada e gozar tudo." (BRECHT, 2004, p. 113). 
de Frank Sinatra ou Elvis Presley, atividades em boa parte promovidas pelo crime organizado como Cosa Nostra e outros grupos mafiosos intimamente relacionados com a política local e nacional (DENTON; MORRIS, 2002).

Em termos sociológicos e culturais, tanto a base de Las Vegas quanto a da cidade Mahagonny são o fordismo, seus trabalhadores e funcionários com carteira assinada, portanto com certo poder aquisitivo, e o entertainment, entretenimento organizado dentro da indústria cultural. " $\mathrm{O}$ conteúdo da ópera Mahagonny é o prazer (Genuss). O caráter de diversão (Spaß), já apontado, revela-se, portanto, não só na forma, como também no tema. [...] O prazer surge, aqui, na sua forma atual e histórica: como mercadoria", declara Brecht nas suas conhecidas notas sobre a ópera (BRECHT, 2005, p. 29-30). Alguns anos mais tarde, exilado em Los Angeles, o autor conheceria a indústria cultural americana por experiência própria.

Las Vegas, entretenimento comercializado e indústria cultural constituem associações não muito promissoras no que diz respeito a uma leitura ecocrítica. Obviamente, Brecht encena em Ascensão e queda da cidade de Mahagonny uma narrativa não sobre o mundo natural em geral, mas sobre a natureza do capitalismo avançado do século XX. No entanto, mesmo se natureza e meio-ambiente não tivessem na peça nenhum papel expressivo, convém lembrar que relações de ordem ecossocial são inerentes a qualquer comunidade humana. Na peça Mahagonny, essas relações não são somente subentendidas, visto que às vezes são explicitamente tematizadas não só em trechos do libreto e em linguagem figurativa do texto, como também na linguagem musical do compositor. A tematização já começa com o título da obra.

\section{Mogno, uma seringueira e a lua verde}

A palavra Mahagonny, na sua ortografia alemã correta Mahagoni, em inglês mahogany, em espanhol caoba, refere-se às árvores produtoras das madeiras conhecidas comercialmente em português como mogno africano ou mogno americano, pertencentes à família botânica Meliaceae. Existe extensa pesquisa filológica a respeito da escolha do título por Brecht; um resumo detalhado dá Jan Knopf na sua apresentação da peça no Brecht Handbuch 1: Stücke (KNOPF, 2001, p. 178-97). Para o público alemão da época, as conotações óbvias da palavra botânica eram colonialismo, exotismo e riqueza. Trata-se de uma madeira avermelhada, popular, porém cara, por ser de origem tropical, geralmente da América Central, América do Sul, ou também de regiões tropicais da Ásia. A associação com o colonialismo confirma-se logo no início do enredo, quando o pequeno grupo em volta da viúva Begbick assume uma atitude de colônia. A chefe decide que vai ocupar o lugar onde eles por acaso pararam, aparentemente terra de ninguém, para fundar uma cidade nova; ato que colonos 
costumam fazer quando chegam ao seu destino para começar a povoar, cultivar e explorar uma terra estrangeira: "Steckt also diesen Angelstock in diese Erde und hisst dieses Stück/Leinen, damit die Schiffe, die von der Goldküste hier vorüberfahren/ Uns sehen können./ Stellt den Bartisch auf/ Dort unterm Gummibaum:/ Das ist die Stadt. / Das ist ihre Mitte. / Und sie heisst: 'Das Hotel zum Reichen Manne'." (BRECHT, 1988, p. 33). ${ }^{2}$

Os fundadores - o trio em volta da viúva Begbick - são criminosos fugitivos e o público-habitante, que logo chega, parece ser constituído não de "homens ricos", mas também de pequenos burgueses e trabalhadores que possuem dinheiro. Florian Vassen salientou o caráter lúdico que a peça assume a partir desse ato fundador teatral: "As a 'stage director' and 'entertainer', Begbick intensifies the theatricality in a show about pleasure, money and death that consists of four staged scenes presented as plays-within-plays" (VASSEN, 2004, p. 276)

A segunda espécie botânica mencionada na peça é uma seringueira, árvore-da-borracha, "Gummibaum" no original alemão. A Ficus elastica foi uma das plantas de decoração interior que mais fez sucesso na Europa no século passado, sendo cultivada com este objetivo, pois não sobreviveria ao ar livre durante o inverno. Muito popular nas casas alemãs, evoca, comparada com a madeira mogno, semelhantes conotações culturais de exotismo e colonialismo. Mais tarde, a partir das profundas mudanças socioculturais dos anos sessenta e setenta na sociedade alemã, a seringueira decorativa vira símbolo de um gosto antiquado, retrógado, em todo caso convencional. De certa forma, Brecht antecipa essa mudança ao levar o protagonista Paul à rebelião contra o convencionalismo do entretenimento barato durante a primeira fase de vida urbana da cidade Mahagonny.

Da freguesia da cidade arapuca, as únicas figuras destacadas com nome são os quatro protagonistas: Paul, Jacob, Heinrich e Joseph (Joe), lenhadores que acabaram de sair do Alaska. Quando entram em cena pela primeira vez, articulam suas exigências materiais e culturais assim: "Auf nach Mahagonny! Die Luft ist kühl und frisch./ Dort gibt es Pferd- und Weiberfleisch/Whisky und Pokertisch/Schöner, grüner/ Mond von Alabama/ Leuchte uns!/ Denn wir haben heute hier/ Unterm Hemde Geldpapier/ Für ein großes Lachen/Deines großen, dummen Munds" (BRECHT, 1988, p. 319-20)3

Todo o quarteto, que forma sozinho essa cena da ópera, consiste em três estrofes, sempre iniciadas por quatro versos diferentes e seguidos pelo refrão que começa com “Bela verde lua". É praticamente idêntico ao

\footnotetext{
2 "Então finquem esta vara de pescar no chão e hasteiem este pano/ Para que as naves vindas da costa de ouro/ Possam nos ver. E o bar será/ Debaixo desta seringueira./ Aqui é a cidade/ Aqui é o centro/ Que se chama: "Hotel do Homem Rico." (BRECHT, 2004, p. 113).

3 "Vou pra Mahagonny/ O ar é puro e fresco!/ Tem carne de cavalo e de mulher,/ Whisky e poker tem também!/ Bela, verde, lua de Alabama, dá a luz!/ Bem no fundo do meu bolso/ Tem dinheiro para pagar/ Tua boca estúpida, que vai logo gargalhar!" (BRECHT, 2004, p. 116-7)
} 
poema-canção „Mahagonnygesang Nr. 1“, na Hauspostille, a antologia poética mais importante do jovem Brecht. Lá o refrão fala da bela lua verde não do Alabama, mas sim de Mahagonny: "Schöner grüner Mond von Mahagonny" (BRECHT, 2002, p. 243). Na obra literária brechtiana, a imagem da lua aparece frequentemente na poesia e também em várias peças teatrais. A lua brechtiana do jovem Brecht da República de Weimar tem as mais variadas colorações (prateada, pálida, vermelha, branca etc.) e sempre denuncia o sentimentalismo barato, o Kitsch. Aqui ela é verde, da cor do absinto e revela-se como uma gigantesca placa de propaganda luminosa (HILLESHEIM, 2013, p. 187), o que indica desde o início o caráter comercial do empreendimento Mahagonny, cidade boa para quem tem dinheiro para pagar. Desse modo, Brecht vai além do simples "Matemos o luar!" de um Marinetti futurista, combatendo contemplação e idílio. Para o autor o anti-ilusionista, teórico do distanciamento e do estranhamento, a lua nos palcos do século XX é pouco mais do que um acessório fabricado que serve para evocar o sentimento previsto. A lua sobre Soho na Ópera de Três Vinténs, obra contemporânea de Mahagonny, não passa de um artifício que o homem de negócios Macheath usa como se ligasse uma lâmpada elétrica:

\footnotetext{
Mac - Und jetzt muss das Gefühl auf seine Rechnung kommen. Der Mensch wird ja sonst zum Berufstier. Setz dich, Polly! Siehst du den Mond über Soho?

Polly - Ich sehe ihn, Lieber. Fühlst du mein Herz schlagen, Geliebter? Mac - Ich fühle es, Geliebte

Polly - Wo du hingehst, da will ich auch hingehen. Mac - Und wo du bleibst, da will ich auch sein.
}

(BRECHT, 2004, p. 41-2) ${ }^{4}$

Nas suas notas publicadas sobre Mahagonny, Brecht observou: "A ópera que nos é dado desfrutar atualmente é uma iguaria" (BRECHT, 2005, p. 28; no original alemão: "eine kulinarische Oper"). Contra um teatro musical culinário, o autor faz uso de uma estética provocativa, às vezes humorística e agressiva ao mesmo tempo, que denuncia o kitsch romântico burguês.

Além do texto e da música, a arte dramática épica brechtiana se manifesta também na cenografia. Um bom exemplo de como Brecht faz uso de elementos da natureza para um cenário anti-ilusionista é a nuvem da cena 9 da ópera Mahagonny. A marcação cênica indica o espaço diante do

\footnotetext{
${ }^{4}$ Mac - E agora é a vez do sentimento. Senão o homem vira um animal de carga. Sente-se, Polly. Vês a lua sobre o Soho?

Polly - Eu vejo, querido. Sentes meu coração bater, amado?

Mac - Eu sinto, amada.

Polly - Para onde fores, eu irei também.

Mac - Para onde fores, eu ficarei também. (BRECHT, 2004, p. 41-2)
} 
Hotel do Homem Rico, onde os homens de Mahagonny estão sentados debaixo de um céu amplo, descansando, bebendo, fumando. "Ouvem música e contemplam, sonhadores, uma nuvem branca que passa no céu, da esquerda para a direita, depois em sentido contrário etc." (BRECHT, 2004, p. 127). Quando Paul Ackermann declara sua discordância com a vida pacata da cidade, o que o faz entrar em conflito aberto com a viúva Begbick, a marcação cênica determina a reação da nuvem branca de papel machê (ou da sua imagem projetada na tela de um Caspar Neher): "A nuvem treme e sai depressa" (BRECHT, 2004, p. 127). Essa nuvem é um dos atributos do tipo de entretenimento oferecido no início da peça Mahagonny - participa da natureza a ser contemplada, mas sempre subordinada ao empreendimento capitalista. A briga de um importante freguês com a dona dos bens e serviços oferecidos na cidade faz ela fugir rapidamente. A confirmação brechtiana "Mahagonny é uma autêntica diversão" (BRECHT, 2004, p. 29), inclui certamente sua maneira de combinar o anti-ilusionismo cênico com bastante humor.

"Maravilhosa é a vida simples,/ E não há nada como a grandiosidade da natureza" (BRECHT, 2004, p. 125), alegam na cena anterior os amigos de Paul, parceiros no trabalho e agora na diversão, Jakob, Heinrich e Joe. A vida em Mahagonny é calma e harmônica, cheia de paz e sossego. Markus Wessendorf associa essa primeira fase de desenvolvimento do empreendimento, quando prevalecem os sentimentos de contemplação e moderação, ao olhar do turista romântico analisado por John Urry: "The romantic form of the tourist gaze, according to Urry, is characterized by 'solitude, privacy and a personal semi-spiritual relationship with the object of the gaze', the most typical of which would be undisturbed natural beauty". (WESSENDORF, 2004, p. 86)

$\mathrm{Na}$ peça, natureza está presente como objeto de consumo estético; todavia, o estético comercializado constitui somente um lado da relação dos homens de Mahagonny com a natureza - o outro lado implica a comercialização material em si. Os quatro protagonistas chegam com os bolsos cheios de dinheiro porque trabalharam como lenhadores sete anos ininterruptos no Alasca, reduzindo a mata nativa da região. Deste modo, a destruição parcial da floresta boreal é pré-requisito da vida contemplativa na cidade de Mahagonny da primeira fase. Na sua obra "O homem unidimensional", Herbert Marcuse estabelece uma ligação entre a abolição da cultura burguesa tradicional junto com a dessublimação de um lado e a colonização e dominação final da natureza, de outro lado: "A abolição da cultura superior é um efeito colateral da conquista da natureza e da progressiva conquista da escassez" (MARCUSE, 2015, p. 96).

A rebelião que o protagonista Paul inicia nas cenas oito e nove se dirige exatamente contra essa vida pacífica: "É demais a calmaria,/ É demais a harmonia,/ E há coisa demais em que se segurar." (BRECHT, 2004 , p. 129). Seu lema constantemente repetido nessa fase do 
empreendimento Mahagonny é: “Mas falta alguma coisa!” („Aber etwas fehlt!"). A natureza como cenário de consumo é uma mentira, fake, como demonstram a lua verde e a falsa nuvem. Paul decide radicalizar o hedonismo pacato agora exige um hedonismo sem limites.

\section{O sublime}

Junto com a rebelião do protagonista anuncia-se, na cena dez, exatamente no meio das vinte cenas da peça, um furacão, o que causa terror na população da cidade. Aqui Weill faz uso de meios da Grande Opera tradicional: os poucos versos são cantados por um coro no estilo de Verdi, lamentando a provável destruição da cidade pelo desastre natural. Libreto e música evocam o influente conceito do sublime. Quando o poder da natureza se revela muito maior do que as forças humanas, trata-se, tradicionalmente, de algo que mal pode ser representado, mas pode ser experimentado na arte em termos estéticos. Lembramos que Kant, na sua terceira crítica, estabelece a diferença entre o sublime que chama de matemático: "denominamos sublime aquilo que é absolutamente grande", melhor: "algo que é grande além de qualquer comparação", (KANT, 2016, p. 144) e o sublime dinâmico da natureza: "Se a natureza deve ser por nós julgada como dinamicamente sublime, ela tem de ser representada como despertando temor" (KANT, 2016, p. 157). Exemplos kantianos do sublime da natureza são rochedos ameaçadores, nuvens carregadas avançando com relâmpagos e trovões, furacões, o oceano ilimitado tomado de fúria etc., todos eles mostrando nossa "insignificante pequenez" (KANT, 2016, p. 158). Kant continua:

Mas a visão que temos deles será tão mais atrativa, quanto mais temíveis eles forem, somente se nos encontrarmos em segurança, e com prazer nós denominamos esses objetos sublimes, pois eles elevam a força da alma acima de sua média habitual e permitem descobrir uma capacidade de resistir de um tipo inteiramente diverso, a qual nos dá coragem para comparar-nos à natureza todo-poderosa. (KANT, 2016, p. 158)

A citação indica que o sublime kantiano aparece muito mais como uma força do nosso ânimo do que uma qualidade intrínseca da natureza. Não se trata, como ainda nas Investigações de Burke, de uma caraterística do objeto, mas de uma sensação mista do observador, que sente medo ou horror e superioridade ao mesmo tempo. Kant conclui: "A sublimidade, portanto, não está contida em coisas da natureza, mas apenas em nossa mente, na medida em que podemos tornar-nos conscientes de sermos superiores à natureza em nós e, portanto (na medida em que ela tem influência sobre nós), também à natureza fora de nós." (KANT, 2016, p. 161). 
O sublime kantiano leva à consciência da nossa superioridade interior. Sabemos reconhecer o terrível, nomeá-lo e dominá-lo - o último às vezes não conseguimos como indivíduos, mas como espécie, já que não somos desamparados, temos nossos meios. O homem é o ser que quer, confirma o kantiano Schiller no início do seu ensaio "Sobre o sublime" (SCHILLER, 2001, p. 55). Isso é exatamente o ponto de vista de Paul Ackermann na ópera Mahagonny. Ele se compara com a natureza todapoderosa em forma da iminente tempestade, anunciando para a viúva Begbick: "Porque eu sou alegre prefiro quebrar suas tabuletas e suas leis e pôr abaixo seus muros. Assim como faz o furacão, eu também faço. Eu pago." (BRECHT, 2004, p. 134) "Para que se precisa de um furacão?" pergunta o protagonista enquanto o coro executa um coral no estilo luterano-protestante. "O que é a fúria de um tufão/ Comparada ao homem quando quer se divertir?" (BRECHT, 2004, p. 131). E ele mesmo dá logo a resposta às suas próprias questões retóricas: "Nós não precisamos de furacão/ [...] Porque todo seu horror/ Nós mesmos podemos fazer." (BRECHT, 2004, p. 132), chegando assim ao lema "Tudo é permitido" (,Du darfst"), que a partir disso seria a norma dos habitantes de Mahagonny até o final. A viúva Begbick resume a questão com clareza: "Schlimm ist der Hurrikan/ Schlimmer ist der Taifun./ Doch am schlimmsten ist der Mensch." (BRECHT, 1988, p. 357). ${ }^{5}$

Formula-se aqui, nas palavras de Paul e da Begbick, um sublime dinâmico novo, mais poderoso do que o sublime kantiano: a natureza social do capitalismo sem limites, em que tudo é permitido enquanto pode ser comercializado. A partir da experiência com o furacão, o projeto inicial de Mahagonny, onde paz e harmonia foram valores centrais, de modo a assegurar assim o fluxo pacífico de bens e serviços, entra na sua segunda fase radicalizada. Tudo é permitido desde que a pessoa tenha os recursos para pagar por isso. Trata-se de um cálculo fatalmente egoísta; o inumano em Mahagonny deriva da "sua Majestade o Eu, o herói de todos os devaneios e de todos romances", como diz Freud no seu ensaio $O$ escritor e a Fantasia (FREUD, 2015, p. 334; v. JAMESON 2013, p. 220). Vale lembrar que na segunda metade dos anos vinte, Brecht não somente começa a estudar Marx, mas é também leitor de Freud, cuja influência na obra brechtiana ainda se encontra pouco pesquisada. Nas suas notas sobre a ópera, Brecht faz, de forma afirmativa, uma longa citação de $O$ mal-estar na civilização, publicado em 1930, ano da estreia da versão definitiva da ópera Mahagonny. Em 1927, Freud tinha publicado O futuro de uma ilusão, onde se lê que "todo indivíduo é virtualmente um inimigo da cultura" (FREUD, 2010, p. 37), e "que é preciso contar com o fato de que em todos os homens há tendências destrutivas, ou seja, antissociais e anticulturais" (FREUD,

5 “Terrível é o furacão/ Mais terrível é o tufão/ Porém, o mais terrível é o homem" (BRECHT, 2004, p. 132). 
2010, p. 39), por causa da sua natureza interior que não aceita facilmente "a coerção ao trabalho e a renúncia aos impulsos" (FREUD, 2010, p. 44).

No final do século $X X$, a ideia do sublime é retomada por um teórico do pós-modernismo, Jean-François Lyotard, que a combina com uma análise crítica do capitalismo tardio ao afirmar que "existe algo de sublime na economia capitalista. Ela não é acadêmica, nem fisiocrática; não admite nenhuma natureza. É, num certo sentido, uma economia regulamentada a partir de uma ideia, a riqueza ou a potência infinita". (LYOTARD, 1997, p. 109).

Diferentemente de Kant e Schiller, o sublime em Lyotard não resulta de uma contribuição ativa do sujeito humano, mas indica um impacto sobre ele, o que implica, de certa maneira, em uma suspensão da capacidade subjetiva. Para Brecht, porém, o poder gigantesco do sublime capitalista está ligado à vontade subjetiva de não reconhecer limites. Quando na cena 8 os amigos de Paul alertam que ele está exagerando, deveria se calmar e aprender de novo a ser gente, o protagonista responde (tranquilamente, como indica a marcação cênica) que não quer ser humano: "Não tenho vontade de ser gente" (BRECHT, 2004, p. 126).

O que significa ser humano? Neste ponto da sua investigação lúdicateatral, bem no meio da peça, Brecht insere dois poemas de sua autoria escritos em 1926 e 1927, que o protagonista Paul declama cantando. O primeiro, que começa com os versos “Não tenham vã esperança / Não há retorno mais" (BRECHT, 2004, p. 133), talvez possa ser considerado o poema mais materialista-ateísta em língua alemã. Trata-se de uma rejeição radical de qualquer esperança cristã em uma continuação da alma depois da morte, no Além: "Lasst euch nicht verführen/Zu Fron und Ausgezehr/Was kann euch Angst noch rühren/Ihr sterbt mit allen Tieren/ Und es kommt nichts nachher." (BRECHT, 1988, p. 358). ${ }^{6}$

Gegen Verführung (contra sedução) parece uma transposição poética da Genealogia da Moral de Friedrich Nietzsche (HILLESHEIM, 2013, p. 229). A poesia que Paul canta logo em seguida, sem intervalo nenhum, combina a rejeição da tradicional moral cristã com a propagação de um hedonismo materialista radical ligado a um capitalismo selvagem que desconhece limites. Trata-se da voz do egoísmo como princípio da vida social que ganha dinâmica ao se juntar à lógica do dinheiro: "Wenn es etwas gibt/Was du haben kannst für Geld/Dann nimm dir das Geld./Wenn einer vorübergeht und hat Geld/ Schlag ihn auf den Kopf und nimm dir sein Geld:/ Du darfst es!" (BRECHT,1988, p. 358). ${ }^{7}$

\footnotetext{
6 "Não caiam nas trapaças/ Da vil exploração,/ Não vem maior desgraça:/ Vocês quais bichos passam -/ É a última canção" (BRECHT, 2004, p. 133).

7 "Quando há algo/ Que podes comprar com grana,/ Pega, então, a grana./ Quando alguém passar com grana,/ Dá-lhe uma paulada e toma a grana,/ Isso é permitido." (BRECHT, 2004, p. 133).
} 
O que prevalece aqui é um darwinismo social sem limites, a lei do mais forte. Na mesma cena 11, escutamos uma variação dessa lei nas famosas palavras cantadas primeiro por Paul, depois repetidas pelo coro de todos: "Denn wie man sich bettet, so liegt man/ Es deckt einen keiner da zu./ Und wenn einer tritt, dann bin ich es/ Und wird einer getreten, bist's $d u !^{\prime \prime}$ (BRECHT, 1988, p. 360). ${ }^{8}$

Essa ligação de hedonismo com capitalismo (KINDT, 2006, p. 550), que se estabelece a partir dos dois poemas citados na segunda parte da peça, tem consequências fatais para o protagonista e toda população de Mahagonny.

\section{Autodestruição}

Das cenas seguintes até o final, a peça desenvolve as consequências individuais e sociais do lema "Tudo é permitido" sob o signo da mercadoria universalizada. Mostram-se no palco os efeitos da satisfação comercial ilimitada das necessidades de comer, amar, lutar fisicamente e beber álcool: „Erstens vergesst nicht, kommt das Fressen/ Zweitens kommt der Liebesakt/ Drittens das Boxen nicht vergessen/Viertens Saufen, das steht im Kontrakt/Vor allem aber achtet scharf/ dass man hier alles dürfen darf" (BRECHT, 1988, p. 362). ${ }^{9}$

O autor mesmo comenta, em 1931: "a obra se esforça em demonstrar o nexo entre a comercialização da diversão (entretenimento, repouso) e seu caráter excessivo" (Brecht apud HENNENBERG; KNOPF, 2006, p.136). Paradoxalmente, o novo sublime dinâmico capitalista leva à dessublimação da moralidade burguesa tradicional, uma dessublimação repressiva, como diria Herbert Marcuse, porque não leva à libertação social e individual, mas ao seu contrário.

Essa problemática já está posta na primeira cena após a cidade ter sido poupada do furacão, quando se encena uma comilança extrema. Recentemente, na sua apresentação do poema "Song of the Taste" do poeta Gary Snyder, um texto que trata do ato de comer como celebração sensual da vida, o ecocrítico Scott Slovic fez uso do termo sustainable poetry (poesia sustentável) e comentou: "Joyful and healthy life, the poet seems to say, does not require an orgy of overeating" (QUIGLEY; SLOVIC, 2018, p. 205). Nesse sentido, o poema de Snyder evoca exatamente o contrário da cena brechtiana. Para Jakob, o morto de fome, a comida é um fetiche e comer num ato compulsivo sem autocontrole, é o que leva à morte por excesso de alimento.

\footnotetext{
8 "Quem faz sua cama, se deita,/ Pois ninguém vive só de mercê;/ E, se alguém sai pisado na vida,/ Não sou eu, esse alguém é você!" (BRECHT, 2004, p. 135).

9 "Vem primeiro a barriga/ E em segundo vem amar,/ Em terceiro vem a briga,/ E beber, em quarto lugar!/ Que fique bem compreendido:/ Aqui é tudo permitido!/ (Quem não tem grana está perdido!)" (BRECHT, 2004, p. 140).
} 
Entende-se que nessa versão operística da fundação de um capitalismo sem limitações não há perspectiva nenhuma para o sentimento de amor. O que existe na cidade Mahagonny é uma linha de produção de sexo: os homens fazem fila para poder realizar um rápido ato sexual pago com uma das moças que vendem seu corpo sob supervisão da empresária chefe. Nesse ambiente ordinário, os amantes Paul e Jenny, que se juntaram a partir de um contrato comercial, cantam o dueto que como poema foi intitulado por Brecht como “Tercetos sobre o amor" (,Terzinen über die Liebe"). Seu estilo de linguagem é elevado e os versos compõem a estrutura de tercetos dantescos não por acaso, visto que relembram a história de Francesca de Rimini e seu amante elaborada por Dante no quinto canto do Inferno da Divina Comédia. O primeiro verso do poema brechtiano, "Veja os grous no céu, em grande arcada!", já evoca os grous do inferno dantesco onde voam em bandos, acompanhando com seu grasnido os lamentos dos pecadores, entre eles Francesca e Paolo. A partir dessas palavras, o público é convidado a participar mentalmente da imagem literária que se desenvolve em seguida (KNOPF, 1996, p. 111; cf. também TATLOW, 2001): trata-se da analogia poética entre os grous voando juntos com as altas nuvens ("Unidos alçam vôo lado a lado", BRECHT, 2004, p. 139) e a vida a dois dos amantes, que no final do poema se revela mais como momento fugaz a dois. $O$ belo natural é evocado em um ambiente social absolutamente deprimente, "onde a coisificação das relações entre os homens contamina toda a experiência" (ADORNO, 1982, p. 109). Herbert Marcuse a respeito da Ópera de Três Vinténs, observou que "Brecht preserva a promesse de bonheur contida no romance e no Kitsch (brilho da lua e o mar azul; melodia e doce lar; lealdade e amor), transformando-a em fermento político" (MARCUSE, 2015, p. 96). Os "Tercetos sobre o amor" associam a promessa da felicidade amorosa com volatilidade, mas ao mesmo tempo a preservam, na letra, como Vor-Schein (Pré-Aparência) no sentido de Ernst Bloch. Considerados um dos mais bem elaborados poemas de amor em língua alemã, os "Tercetos" guardam a força de uma imagem poética sugestiva que implica tanto a humanização da natureza quanto a naturalização do ser humano representado pelo casal.

Como já indica o título da ópera, a cidade de Mahagonny, modelo de uma comunidade determinada pela ideologia do dinheiro, está condenada ao fracasso. No decorrer da trama, a união entre os dois amantes se desfaz quando Paul é condenado "por não ter dinheiro/ O que é o maior crime/ Sobre a face da terra" (BRECHT, 2004, p. 155). Sua amante e seu melhor amigo Heinrich se recusam a ajudar a pagar suas contas e o protagonista é eletrocutado em praça pública. Finalmente, Paul compreende a ilusão de uma maneira de viver que se diz hedonista, mas se baseia exclusivamente no consumo pago: "A felicidade que comprei não era felicidade, e a liberdade que eu tive à custa de dinheiro não era liberdade. Eu comia e não matava a fome, eu bebia e ficava com mais sede." (BRECHT, 2004, p. 160). 
A cena 16, em o processo que levaria à morte o protagonista desencadeiase, tem o mote "Beber" (Saufen). Quando chega a hora de Paul pagar a conta da bebedeira coletiva, ele tenta escapar de Mahagonny, ao se refugiar em um sonho diurno, parecido com aquele da Jenny-Pirata na "Ópera de três vinténs". Diferentemente da Jenny, Paul não simplesmente evoca o navio salvador cantando, mas encena uma representação teatral dentro do palco com participação dos amigos presentes (para Florian Vassen um exemplo, entre outros, que mostra a "teatralidade potencializada" da peça Mahagonny, cf. VASSEN, 2004). No final da pequena viagem imaginária chega-se à terra prometida, "as florestas do Alasca./ Desembarquem agora./ Estamos salvos." A tentativa de escapar leva ao retorno à natureza selvagem, dessa vez não para ganhar dinheiro derrubando mata nativa, mas para fugir da civilização capitalista. Contudo, em Mahagonny não existe fuga para quem não tem dinheiro e o destino de Paul está selado.

$\mathrm{Na}$ última cena vê-se a ruína da cidade, onde a vida social entra em colapso, por consequência da luta de todos contra todos. Os habitantes cantam: "Wir brauchen keinen Hurrikan/Wir brauchen keinen Taifun,/Was der an Schrecken tuen kann / Das können wir selber tun" (BRECHT, 1988, p. 387). ${ }^{10}$

A cidade não é, portanto, devastada por catástrofes naturais, mas pelos impulsos autodestrutivos inerentes a uma vida social sob o signo do capitalismo.

\section{Observações finais}

Brecht escreveu durante sua vida inteira poesia sobre o mundo natural, principalmente sobre árvores. Essa produção poética iniciou-se na adolescência - a coletânea completa dos seus poemas começa com uma obra juvenil intitulada A árvore em chamas (Der brennende Baum, de 1913) estendendo-se até as Elegias de Buckow dos anos cinquenta e poemas ainda posteriores, como "Tempos difíceis" („Schwierige Zeiten“), em que o eu lírico lembra-se de um sabugueiro da sua infância em Augsburg. No longo poema "Aos que vão nascer" (,An die Nachgeborenen“, 1937), o último da coletânea Poemas de Svendborg, o autor inicia a segunda estrofe com os seguintes versos famosos: „Was sind das für Zeiten, wo/ Ein Gespräch über Bäume fast ein Verbrechen ist/ Weil es ein Schweigen über so viele Untaten einschliesst!" (BRECHT, 2002, p. 723).11

São tempos sinistros, finstere Zeiten. A natureza aqui tem a função do Outro da sociedade humana, fora do alcance dos regimes fascistas e stalinistas em que reina a barbárie e os mais terríveis crimes são cometidos.

\footnotetext{
10 “Nós não precisamos de furacão/ Nem precisamos de tufão,/ Porque todo horror de seu poder/ Nós mesmos podemos fazer. (BRECHT, 2004, p. 161)

11 "Que tempos são esses, em que/ Falar de árvores é quase um crime/ Pois implica silenciar sobre tantas barbaridades?" (BRECHT, 2000, p. 212).
} 
Essa perspectiva sobre o mundo natural já encontramos em Mahagonny, peça que leva o nome de uma espécie de árvore, mas trata da barbaridade de uma sociedade que instalou o hedonismo pago, a comercialização total, como princípio fundamental das relações sociais.

No antropoceno do século XXI, a dicotomia sociedade vs. natura está desaparecendo, uma vez que não existe mais natureza fora do alcance da manipulação tecnocientífica. A barbárie que se aproxima, para usar uma expressão de Isabelle Stengers (STENGERS, 2015), tem sua causa na devastação ambiental planetária, provocada pela nossa maneira capitalista de produzir e consumir em nível global sem considerar as consequências para o meio-ambiente e aceitar limites de crescimento. Capitalismo "is a way of organizing nature", como tem lembrado Jason W. Moore (MOORE, 2015, p. 2). Assim, cerca de noventa anos depois da encenação da autodestruição da cidade arapuca Mahagonny no palco brechtiano, a eliminação de uma parcela numerosa da humanidade por catástrofes naturais é uma perspectiva real. A destruição, por exemplo por furacões cada vez mais frequentes, é uma das consequências do aumento das emissões de gases de efeito estufa na atmosfera.

Os impulsos autodestrutivos inerentes a uma vida social sob o signo da mercadoria universalizada, do desenvolvimento econômico ilimitado, do progresso como ideologia, abrangem diretamente a natureza. "We've lost our good old mamma" (BRECHT, 2005, p. 114); estamos tratando a mãe terra tão mal que ela começou a vingar-se. Em Mahagonny, Brecht põe em cena uma mudança histórica, visto que o agir dos habitantes da cidade não é mais determinado pelas circunstâncias naturais, pela primeira natureza, mas por aquilo que na tradição de Hegel e Adorno se chama segunda natureza: as relações sociais construídas entre os humanos. No entanto, tudo indica que atualmente chegamos a uma situação onde podemos inverter a pergunta retórica do protagonista Paul Ackermann desta maneira: o que é um homem que quer se divertir, comparado à fúria de um tufão?

Na perspectiva ecocrítica aqui desenvolvida, a peça brechtiana sobre a união fatal da natureza interior do ser humano, dos seus impulsos sociobiológicos, com o poder "natural" do dinheiro, com a força destruidora de um capitalismo que age sem escrúpulos, parece mais atual do que nunca. Recentemente, Isabelle Stengers tem afirmado: "Lutar contra Gaia não tem sentido, trata-se de aprender a compor com ela. Compor com o capitalismo não tem sentido, trata-se de lutar contra seu domínio" (STENGERS, 2015, p. 47). Essa é uma observação Brecht que certamente assinaria. 


\section{Referências bibliográficas}

BRECHT, Bertolt. Estudos sobre teatro. Trad. de Fiama Pais Bransão. Rio de Janeiro: Nova Fronteira, 2005 ( $2^{\mathrm{a}}$ ed.).

BRECHT, Bertolt. Teatro Completo. Rio de Janeiro: Paz e Terra, 2004, v. 3.

BRECHT, Bertolt. Poemas 1913-1956. Trad. de Paulo César de Souza. São Paulo: Ed. 34, 2000.

BRECHT, Bertolt. Große kommentierte Berliner und Frankfurter Ausgabe. Stücke 2. Berlin u. Weimar: Aufbau; Frankfurt a.M.: Suhrkamp, 1988.

BRECHT, Bertolt. Die Gedichte von Bertolt Brecht in einem Band. Frankfurt a. M.: Suhrkamp 2002.

DENTON, Sally; MORRIS, Roger. The money and the power: the making of Las Vegas and its hold on America. Nova Iorque: Vintage, 2002.

FREUD, Sigmund. "O escritor e a fantasia". In: Obras completas, v. 8, 19061906. Trad. de P. C. de Souza. São Paulo: Companhias das letras, 2015; p. 325-38.

FREUD, Sigmund. O futuro de uma ilusão. Trad. de Renato Zwick. Porto Alegre: L\&PM, 2010.

HENNENBERG, Fritz; KNOPF, Jan (eds.). Brecht/Weill Mahagonny. Frankfurt a.M.: Suhrkamp, 2006.

HILLESHEIM, Jürgen. Bertolt Brechts Hauspostille: Einführung und Analysen sämtlicher Gedichte. Wurtzburgo: Königshausen \& Neumann, 2013.

JAMESON, Frederic. Brecht e a questão do método. Trad. de Maria Sílvia Betti. São Paulo: Cosac \& naify, 2013.

KINDT, Tom. „Die Politisierung Brechts und die Urbanisierung Baals“: Anmerkungen zur Interpretation der Oper 'Aufstieg und Fall der Stadt Mahagonny'. In: KOCH 2006, p. 50-9.

KNOPF, Jan. Gelegentlich: Poesie. ein Essay über die Lrik Bertolt Brechts. Frankfurt a.M.: Suhrkamp, 1996.

KNOPF, Jan (ed.). Brecht Handbuch Band 1: Stücke. Stuttgart; Weimar: Metzler, 2001.

KNOPF, Jan (ed.). Brecht Handbuch Band 2: Gedichte. Stuttgart, Weimar: Metzler, 2001.

$\mathrm{KOCH}$, Gerd et. allii (eds.). "Können uns und euch und niemand helfen" - Die Mahagonnysierung der Welt: Bertolt Brechts und Kurt Weills "Aufstieg und Fall der Stadt Mahagonny“. Frankfurt a. M.: Brandes \& Apsel, 2006.

LYOTARD, Jean-François. O inumano: considerações sobre o tempo. Lisboa: Ed. Estampa, 1997 (2 $2^{a}$ ed.).

MARCUSE, Herbert. O homem unidimensional: estudos da ideologia da sociedade industrial avançada. Trad. de R. de Oliveira. São Paulo: Edipro, 2015 (1964).

MOORE, Jason W. Capitalism in the web of life: ecology and the accumulation of capital. Londres; Nova Iorque: Verso, 2015. 
QUIGLEY, Peter; SLOVIC, Scott (eds.). Ecocritical aesthetics: language, beauty, and the environment. Bloomington: Indiana UP, 2018.

SCHILLER, Friedrich. "Sobre o sublime". In: Do sublime ao trágico. Org. e trad. de Pedro Süssekind. Belo Horizonte: Autêntica, 2011, 53-74.

SILBERMAN, Marc; VASSEN, Florian (eds.). Mahagonny.com. The Brecht Yearbook 29. Madison: University of Wisconsin Press, 2004.

STENGERS, Isabelle. No tempo das catástrofes: resistir à barbárie que se aproxima. São Paulo: Cosac \& naify, 2015.

TATLOW, Antony. „Terzinen über die Liebe“. In: KNOPF, Jan. Brecht Handbuch Band 2: Gedichte. Op. cit, p. 168-72.

VASSEN, Florian. „Potenzierte Spiele und tödliche Inszenierungen“: Bertolt Brechts Aufstieg und Fall der Stadt Mahagonny. In: SILBERMAN; VASSEN 2004, p. 276-90.

Recebido em 23 de maio de 2020

Aprovado em 8 de junho de 2020

Klaus F. W. Eggensperger é professor de Literatura e Estudos Culturais da área de Inglês e da Pós-graduação em Letras na Universidade Federal do Paraná. Doutorou-se em Linguística na Universidade de Osnabrück (Alemanha) e publicou, entre outros trabalhos, Modale Nebenverben im Jiddischen. Eine korpusgestützte Untersuchung zu 'soln' und 'wolt' (1995). Em 2017, fundou na UFPR o Grupo de Estudos Ecocríticos GECO (https://www.grupoecocritico.com.br). Contato: klausegge@gmail.com

ORCiD: https://orcid.org/0000-0003-4484-8874 